\title{
Inability to walk and persistent thigh pain after transobturator tape procedure for stress urinary incontinence: surgical management
}

\author{
Rodolfo Milani $^{1,2} \cdot$ Marta Barba $^{1}$ (I) $\cdot$ Stefano Manodoro ${ }^{3} \cdot$ Luca Locatelli $^{1} \cdot$ Stefania Palmieri $^{1} \cdot$ Matteo Frigerio $^{2}$
}

Received: 10 November 2020 / Accepted: 22 December 2020 / Published online: 3 March 2021

(C) The International Urogynecological Association 2021

\begin{abstract}
Introduction and hypothesis Groin pain after transobturator tape is often a self-limiting situation, but can occasionally persist and be associated with serious neurological sequelae. The video is aimed at presenting the surgical management of persistent groin pain and inability to walk after transobturator sling placement and subsequent partial removal.

Methods The featured patient is a 31-year-old woman unable to walk after transobturator sling implantation 2 years before. She reported left thigh pain immediately after surgery that was not responsive to postoperative medication. Six months later, suburethral portion excision was performed but no pain relief was obtained. She was unable to walk, and needed a wheelchair. Electromyography showed axonal injury of the left obturator nerve. After providing proper informed consent, the patient was admitted for combined transvaginal and transcutaneous transobturator tape arm removal.

Results The featured procedure was completed in $120 \mathrm{~min}$ and blood loss was $<100 \mathrm{ml}$. No surgical complications were observed. The patient is currently doing left leg rehabilitation, has regained the ability to walk with the aid of a crutch, and the need for chronic pain control medication is greatly reduced.

Conclusion This represents a valid surgical approach for the late management of this mesh-related complication.
\end{abstract}

Keywords Transobturator tape $\cdot$ Midurethral sling $\cdot$ Stress urinary incontinence $\cdot$ Anti-incontinence surgery $\cdot$ Video tutorial

\section{Introduction}

Synthetic midurethral slings represent effective procedures for the treatment of stress urinary incontinence. However, several complications have been described, including major bleeding, bladder perforation, and groin pain [1,2]. The latter is associated with the transobturator route and involves either direct damage or sling-induced tension on the obturator neurovascular bundle. Although in the majority of cases postoperative groin pain is self-limited, persistent and intractable pain has also been described [1]. In this case, it can lead to serious and disabling consequences, including the inability to walk and severe deterioration of quality of life. Surgical management of persistent

Marta Barba

m.barba8792@gmail.com

1 University of Milano-Bicocca, Monza, Italy

2 ASST Monza, Ospedale San Gerardo, via G.B. Pergolesi, 33 20900, Monza, Italy

3 ASST Santi Paolo e Carlo, Milan, Italy groin pain can be difficult, and it may not be possible to achieve pain relief [3]. Moreover, when functional deficits have arisen, outcomes are even more uncertain. There is no general agreement on the best surgical approach to obturator tape removal in these patients: transvaginal, transcutaneous, combined, or transabdominal routes may be suitable [4]. The video is aimed at presenting a case of surgical management of persistent groin pain and inability to walk after transobturator sling placement and subsequent partial removal.

\section{Method}

A 31-year-old woman was referred to our Unit for left pelvic pain and inability to walk after transobturator sling GYNECARE TVT ${ }^{\mathrm{TM}}$ ABBREVO® (Ethicon Cincinnati, OH, USA) implantation about 2 years before in a hospital of another administrative region of Italy. Details of procedure as well as intraoperative complications were not available. Her general clinical history was unremarkable. She reported left thigh pain immediately after surgery that did not respond to postoperative medication. Six months after the procedure, 
suburethral portion excision was performed but no pain relief was obtained, and stress urinary incontinence recurred. At the time of our evaluation, she was in a wheelchair owing to her inability to walk and chronic left thigh pain. She was on chronic analgesic therapy with oxycodone, pregabalin, and fentanyl. She had already undergone electromyography, which showed axonal injury of the left obturator nerve, and pelvic MRI, which revealed the presence of a $3-\mathrm{cm}$ portion of the tape associated with fibrosis and retraction on the left obturator neurovascular bundle. During gynecological examination, the sling was not identifiable. Regular vaginal trophism was observed but intense pain was elicited by palpation of the left lateral vaginal fornix and the medial side of the obturator foramen. Transperineal ultrasound confirmed the presence in situ of the left arm of the sling, which was located at a minimum distance of $15 \mathrm{~mm}$ and $20 \mathrm{~mm}$ from the vaginal mucosa and the skin respectively. Cystoscopy did not demonstrate evidence for mesh within the bladder.

In consideration of the failure of conservative management and the presence of muscular deficit, we decided-after obtaining proper informed consent - to admit the patient for combined transvaginal and transcutaneous left portion tape removal. Broad-spectrum antibiotic prophylaxis and thromboprophylaxis were administered preoperatively. The patient received general anesthesia and was placed into the lithotomy position. An indwelling transurethral catheter was positioned. An orthopedic colleague was called to assist with the identification of inner thigh anatomical landmarks.

The following surgical steps were then performed:

1. A left paraurethral colpotomy was performed and blunt dissection carried out until the medial edge of the left tape arm was identified and marked with a Kocher clamp.

2. Gentle traction was performed with the Kocher clamp to perform initial tape dissection from the surrounding tissue.

3. An approximately $5-\mathrm{cm}$ incision was made $1 \mathrm{~cm}$ lateral to the inferior pubic ramus and electrocautery was used on the subcutaneous tissue until the gracilis muscle was exposed.

4. The gracilis muscle was detached at the level of the inferior pubic ramus and the adductor brevis muscle was exposed.

5. The adductor brevis muscle was detached at the level of the inferior pubic ramus and the obturator externus muscle was exposed.

6. Systematic palpation of the obturator externus muscle associated with gentle traction of the medial edge of the left tape arm allowed for identification of the left portion of the sling, which appeared dislocated more lateral and deeply than the expected path.

7. Once the sling was identified, it was carefully dissected and freed from surrounding tissue.
8. The gracilis muscle and the adductor brevis muscle insertions on the inferior pubic ramus were restored with interrupted absorbable sutures; a "Penrose" drain was placed deep in the thigh incision.

9. The layered closure of the thigh and vaginal skin incisions completed the procedure.

\section{Results}

The featured procedure was completed in $120 \mathrm{~min}$ and blood loss was $<100 \mathrm{ml}$. No surgical complications were observed. The drain was removed on postoperative day 1. On postoperative day 3 , the patient was successfully discharged home. Outpatient rehabilitation was started 3 weeks after discharge, but it was discontinued for some months owing to the COVID-19 pandemic. At the current follow-up (7 months), the patient is still doing left leg rehabilitation and has regained the ability to walk with the aid of a crutch, and the need for chronic pain control medication is greatly reduced. Stress urinary incontinence was unmodified in terms of severity compared with baseline, and the patient is scheduled for repeat anti-incontinence surgery.

\section{Discussion}

Surgical removal of the obturator arm of a transobturator tape can be a demanding procedure, especially after partial sling removal. In the featured patient we were able to remove the obturator portion and obtain partial relief of symptoms, even 2 years after implantation. Groin pain after transobturator tape is described in up to $9.7 \%$ [5]. Often, it is a self-limiting situation, but can occasionally persist and have very disabling consequences. Initial management involves pain control medications and close follow-up. In the case of persisting symptoms, early (7-10 days after the procedure) tape cut is advisable and is usually effective at relieving tension and pain relief. Options for chronic pain include nerve blockage and late surgical management. A case series of 8 patients with refractory neurological symptoms a mean of 2.7 years after TOT slings supported the notion that thigh dissection with unilateral or bilateral mesh removal could be offered, with symptom improvement, even years after the index surgery [3]. The concomitant vaginal portion of the mesh excision should be considered in the case of concomitant vaginal pain [3]. While obturator arms excision is performed, it is not uncommon to find that the tape path is different from that expected, similar to what we experienced in the featured patient. In two prior series mesh was found incorrectly placed, involving the adductor longus tendon and the obturator nerve in some cases [6, 7]. However, King et al. [3] in their series reported only one 
case in which the obturator arm was found abnormally positioned (above the adductor longus tendon) suggesting that pain might often be related to local inflammatory response rather than to grossly incorrect positioning. A possible strategy for reducing morbidity on the obturator neurovascular bundle while maintaining the advantages of a transobturator path is to perform single-incision sling procedure instead, which avoids the passage of tape and trocar through the obturator foramen, adductor tendons, and skin [8]. Advantages include the ease of the procedure and the minimal complication rate, even with a long-term follow-up $[9,10]$. However, the widespread use of single-incision slings is limited by the absence of robust long-term data. Moreover, timely referral for highvolume pelvic floor surgery may be critical to allow prompt management and limit long-term sequelae. Last, this step-bystep video tutorial may represent an important tool for improving surgical know-how, thus spreading knowledge about the management of this potentially severe complication.

\section{Conclusion}

The featured video shows the surgical management of persistent groin pain and inability to work 2 years after transobturator tape placement and subsequent partial sling removal. The obturator portion of the sling was successfully removed through a combined transvaginal-transcutaneous approach. The surgery resulted in partial relief of the pain described by the patient and recovery of the ability to walk. This approach represents a valid procedure for the surgical management of this mesh-related complication. However, timely referral to providers trained to deal with these complications is of the utmost importance.

Supplementary Information The online version of this article (https://doi. org/10.1007/s00192-020-04666-x) contains supplementary material. This video is also available to watch on http://link.springer.com/. Please search for this article by the article title or DOI number, and on the article page click on 'Supplementary Material'

\section{Declarations}

Conflicts of interest None.
Consent Written informed consent was obtained from the patient for publication of this video article and any accompanying images.

\section{References}

1. Gruber DD, Hernandez SL, Wright J Jr, Fischer JR. Transobturator tape removal using a combined vaginaltranscutaneous approach for intractable groin pain. Female Pelvic Med Reconstr Surg. 2011;17(1):55-7. https://doi.org/10. 1097/SPV.0b013e318204490c.

2. Milani R, Manodoro S, Cola A, Palmieri S, Frigerio M. Management of unrecognized bladder perforation following suburethral tape procedure. Int J Gynaecol Obstet. 2018;142(1): 118-9. https://doi.org/10.1002/ijgo.12493.

3. King AB, Tenggardjaja C, Goldman HB. Prospective evaluation of the effect of thigh dissection for removal of transobturator mid urethral slings on refractory thigh pain. J Urol. 2016;196(4): 1207-12. https://doi.org/10.1016/j.juro.2016.03.153.

4. Siddharth A, Hussain MJ, Cartwright R, Jackson S, Price N. A novel technique for complete laparoscopic excision of a transobturator sling with lower urinary tract mesh erosion. Int Urogynecol J. 2020;31(4):839-41. https://doi.org/10.1007/ s00192-020-04264-x.

5. Brubaker L, Norton PA, Albo ME, Chai TC, Dandreo KJ, Lloyd $\mathrm{KL}$, et al. Adverse events over two years after retropubic or transobturator midurethral sling surgery: findings from the Trial of Midurethral Slings (TOMUS) study. Am J Obstet Gynecol. 2011;205(5):498.e1-6. https://doi.org/10.1016/j.ajog.2011.07.011.

6. Rigaud J, Pothin P, Labat JJ, et al. Functional results after tape removal for chronic pelvic pain following tension-free vaginal tape or transobturator tape. J Urol. 2010;184:610.

7. Reynolds WS, Kit LC, Kaufman MR, et al. Obturator foramen dissection for excision of symptomatic transobturator mesh. J Urol. 2012;187:1680.

8. Spelzini F, Cesana MC, Verri D, Polizzi S, Frigerio M, Milani R. Three-dimensional ultrasound assessment and middle term efficacy of a single-incision sling. Int Urogynecol J. 2013;24(8):1391-7. https://doi.org/10.1007/s00192-012-2031-5.

9. Spelzini F, Frigerio M, Regini C, Palmieri S, Manodoro S, Milani $\mathrm{R}$. Learning curve for the single-incision suburethral sling procedure for female stress urinary incontinence. Int J Gynaecol Obstet. 2017;139(3):363-7. https://doi.org/10.1002/ijgo.12317.

10. Frigerio M, Milani R, Barba M, Locatelli L, Marino G, Donatiello $\mathrm{G}$, et al. Single-incision slings for the treatment of stress urinary incontinence: efficacy and adverse effects at 10-year follow-up. Int Urogynecol J. 2021;32(1):187-91.

Publisher's note Springer Nature remains neutral with regard to jurisdictional claims in published maps and institutional affiliations. 